\title{
Photocatalytic removal of 2,4,6-trichlorophenol from water exploiting commercial $\mathrm{ZnO}$ powder.
}

\begin{abstract}
2,4,6-trichlorophenol is an important water pollutant owing to the severity of its toxicity. The aqueous phase photocatalytic oxidation of 2,4,6-trichlorophenol over $\mathrm{ZnO}$ was investigated as a potential method for the abatement of this pollutant. The effects of operating parameters such as initial $\mathrm{ZnO}$ doses and substrate concentration on the removal of 2,4,6-trichlorophenol were studied and optimised at $0.75 \mathrm{~g} \mathrm{~L}-1$ and $50 \mathrm{mg} \mathrm{L}-1$, respectively. The photocatalytic system afforded the highest degradation efficiency at neutral $\mathrm{pH}$. The decomposition of 2,4,6trichlorophenol by the photoprocess agreed satisfactorily with pseudo zero-order kinetic model. The effect of the presence of SO42-, S2O82-, HPO42- and $\mathrm{Cl}-$ on the 2,4,6trichlorophenol removal rate was for the first time revealed. Some hitherto unreported pathway intermediates of $\mathrm{ZnO}$-assisted 2,4,6-trichlorophenol degradation were recorded using gas chromatography-mass spectrometry (GC-MS) and high performance liquid chromatography (HPLC). A tentative reaction mechanism for the formation of these intermediates was proposed.
\end{abstract}

Keyword: Photocatalysis; Intermediates; 2,4,6-Trichlorophenol removal; ZnO; Anions. 